\title{
FULL LENGTH RESEARCH ARTICLE \\ THE EFFECT OF SEED MASS AND COTYLEDON REMOVAL ON THE GERMINATION AND GROWTH OF FLUTED PUMPKIN (Telfaria occidentalis Hook. F)
}

\author{
IORTSUUN, D. N. *CHIA, A. M. \& ADEOLA, A. F. \\ Department of Biological Sciences, Ahmadu Bello University \\ Zaria, Nigeria \\ *(Corresponding author) \\ chia28us@vahoo.com
}

\begin{abstract}
Experiments were carried out to determine the effect of seed mass and cotyledon removal on the germination and growth of African fluted pumpkin (Telfaria occidentalis, Hook. F.). The seeds of pumpkin were divided into 3 weight classes A (13.10$13.05 \mathrm{~g}), \mathrm{B}(11.10-11.05 \mathrm{~g}), \mathrm{C}(8.60-8.55 \mathrm{~g})$ and planted in a 1:1 mixture of soil and sawdust, and the following parameters observed: germination rate, seedling height, number of leaves produced, leaf area index, fresh and dry weight of seedlings. Except for leaf area index, it was found that the seeds with the highest weight showed superiority over the seeds of the other weight classes based on the results of Analysis of variance (ANOVA) at $P \geq 0.05$. The removal of one and two cotyledons had adverse effect on the seedling growth. The plants with their two cotyledons removed both before and after first foliage leaves emergence showed the least seedling growth. The seed mass was strongly positively correlated with the observed parameters. These results show that seedlings originating from large seeds can better endure loss of cotyledons and aerial biomass and are thus better adapted to withstand cotyledon damage due to soil fauna and other deteriorating factors in the early stage of life.

Key words: Seed mass, Cotyledon removal, Telfaria occidentalis, Fluted Pumpkin, Germination, Growth
\end{abstract}

\section{INTRODUCTION}

Seed mass plays a vital role in reproductive biology (Cordazzo 2002). Research has revealed that there is great variation of seed mass both within and between species and even in an individual plant (Leishman \& Westby 1994). Bonfil (1998) reported that seedling survival was greatly affected by excision of cotyledons of Quercus rugosa and $Q$. laurina. Carbon supplies from cotyledons and other carbohydrates reserves apparently enhanced ability of seedlings to cope with herbivory, pests and diseases (Kitajima 2003).

There is evidence that differential seed sizes have various important ecological implications (Cordazzo 2002). For example, seed germination and germination rate are greatly correlated with seed mass (Weis 1982; Zhang \& Mann, 1991). Large seeds frequently have greater percent germination when compared with the small seeds (Hendrix 1984, Westoby et al. 2002). The effect of seed mass can further be reflected by seedling biomass (Zimmerman \& Weis 1983; Dalling \& Hubbell 2002; Westoby et al. 2002). When cotyledons are removed from seeds of different species it affects their growth, survival and soil penetration (Lamont \& Milberg 1997: Moles \& Westoby 2004).

Telfaria occidentalis is a good supplement of melon and soybean. The plant is noted to have problems of germination due to soil worms and nematodes eating up the cotyledons. The cotyledons form the bulk of the seeds; therefore destruction would affect the germination and subsequent growth and establishment of the seedling. Considering the long time it takes to produce fruit (8-10 months) and the few number of fruits produced (2-5 per plant), it is imperative that studies should be carried out on this plant to discover ways of increasing its yield.

The cotyledon of the seedlings of African Fluted Pumpkin, $T$. occidentalis Hook. F are often damaged during fruit storage and are also eaten up by soil fauna when planted directly. This research was carried out to determine the effect of seed mass and cotyledon removal on its germination and growth.

\section{MATERIALS AND METHODS}

Plant materials and Planting: The experiment was carried out for four (4) weeks in the Department of Biological, Ahmadu Bello University, Zaria, Nigeria (Longitude 7038' $\mathrm{N}$ and Latitude 110 11' E). The land was cleared of grasses, ploughed and watered. The soils were mixed with sawdust at 1:1 ratio and further watering carried out twice a day. The sawdust aided easy uprooting of the seedling plant during the experiment.

The seeds of African Pumpkin were weighed and divided into 3 different weight classes A, B and C (13.10-13.05g, 11.10-11.05g, and $8.60-8.55 \mathrm{~g}$ respectively). For each class weight 29 seeds were used for the experiments. To test the effect of seed size on fresh and dry weights of seedling plant, a total of 36 seeds were planted using 12 seeds from each weight class and their germination rate noted. Four plants were randomly uprooted on the $5^{\text {th }}$ day after germination and the fresh and dry weight taken. Sampling was repeated at five day interval.

On another bed, 15 seeds were planted using 5 seeds from each weight class to test for the effect of seed weight on seedling growth. The height of the seedlings, rate of leaf production and leaf area were taken for about 2 weeks at a 2 day interval. Furthermore, experiments to test for the effect of cotyledon removal were carried out on a third seed bed. 36 seeds were planted using 12 seeds from each weight class. When the seed germinated, their cotyledons were removed at different ages of the seedling in the following order: 
Removal before and after emergence of the first foliage leaves and this was subdivided into two groups: (i) one cotyledon removed and (ii) two cotyledons removed.

Experimental Design: The experimental design was a split-plot design with class weight being the main plot and number of cotyledon removed being the subplots. Observation was carried out on the heights and leaf production of the seedlings.

Statistical Analysis: Analysis of Variance (ANOVA) was used to test for difference between weight classes for the observed parameters while Pearson's correlation coefficient was used to test for the relationship between the observed parameters and seed mass.

\section{RESULTS}

Effect of Seed mass on germination and seedling growth: The seeds with the highest weight had a higher seedling height and number of leaves produced (Figs. 1 \& 2). Next to this was the medium weight class while the lowest weight class had the least performance in terms of germination and seedling growth. These differences were found not to be significant between the class weights over time ( $F=0.2458$, Table 1). For the leaf production rate, the differences between the class weight was highly significant ( $F=21.37$, Table 1$)$ as the largest seeds produced more leaves followed by the medium sized seeds and finally the smallest seeds.

TABLE 1. ANOVA SUMMARY FOR ALL THE OBSERVED PARAMETERS AT $P \leq 0.05$

\begin{tabular}{lll}
\hline Parameter & F Calculated & F Table \\
\hline Seedling Height & 0.246 & 3.080 \\
Leaf Number & 21.37 & 3.080 \\
Leaf Area & 4.184 & 3.124 \\
Seedling growth (cotyledons removed before & 108.890 & 3.555 \\
emergence of foliage leaves) & & \\
Seedling growth (cotyledons removed after & 68.145 & 3.555 \\
emergence of foliage leaves) & & \\
Fresh Seedling Weight & 6.1612 & 6.944 \\
Dry Seedling Weight & 3.432 & 6.944 \\
\hline
\end{tabular}

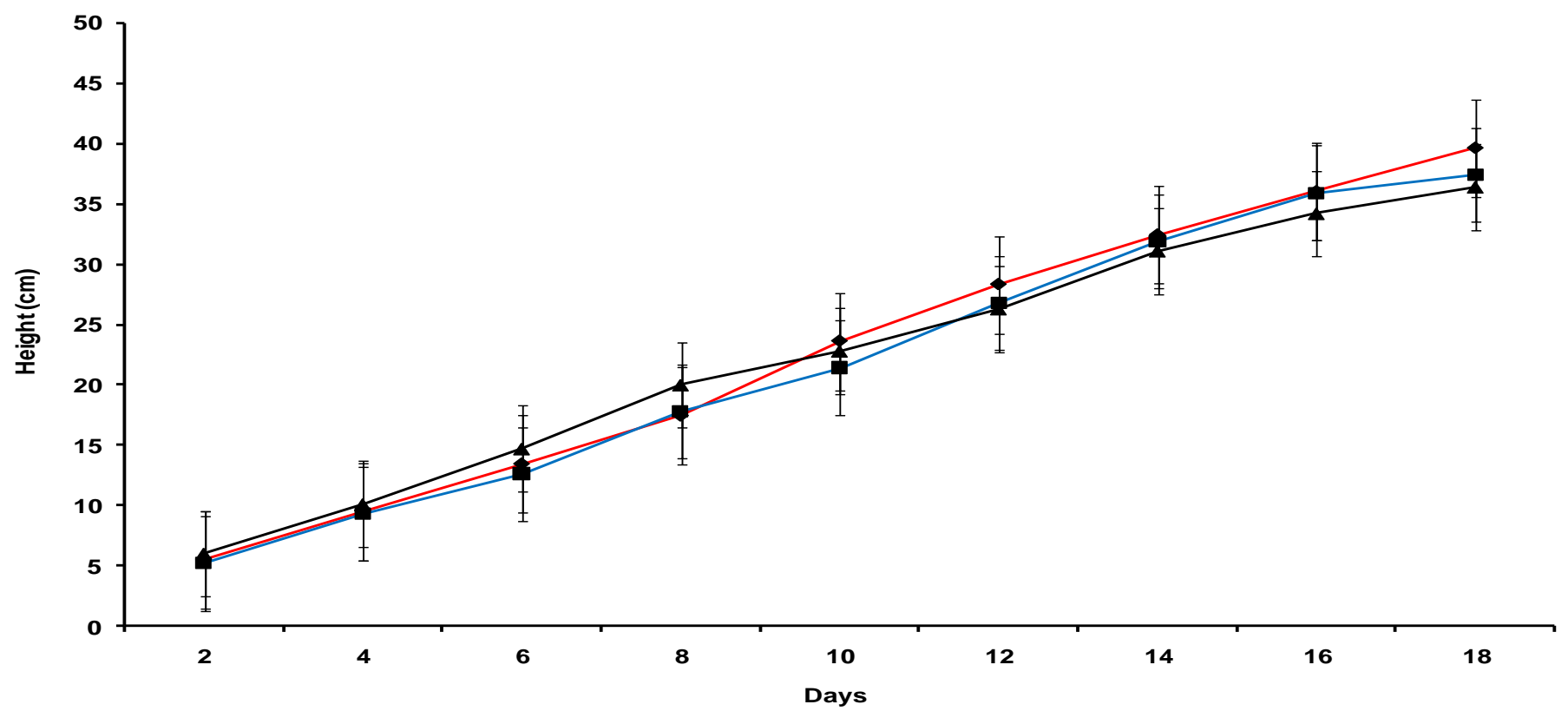

$\multimap \mathrm{A}(13.10-13.05) \rightarrow-\mathrm{B}(11.10-11.05) \rightarrow \mathrm{C}(8.60-8.55)$

FIG. 1. SEEDLING HEIGHT ACCORDING TO THEIR WEIGHT CLASSES 


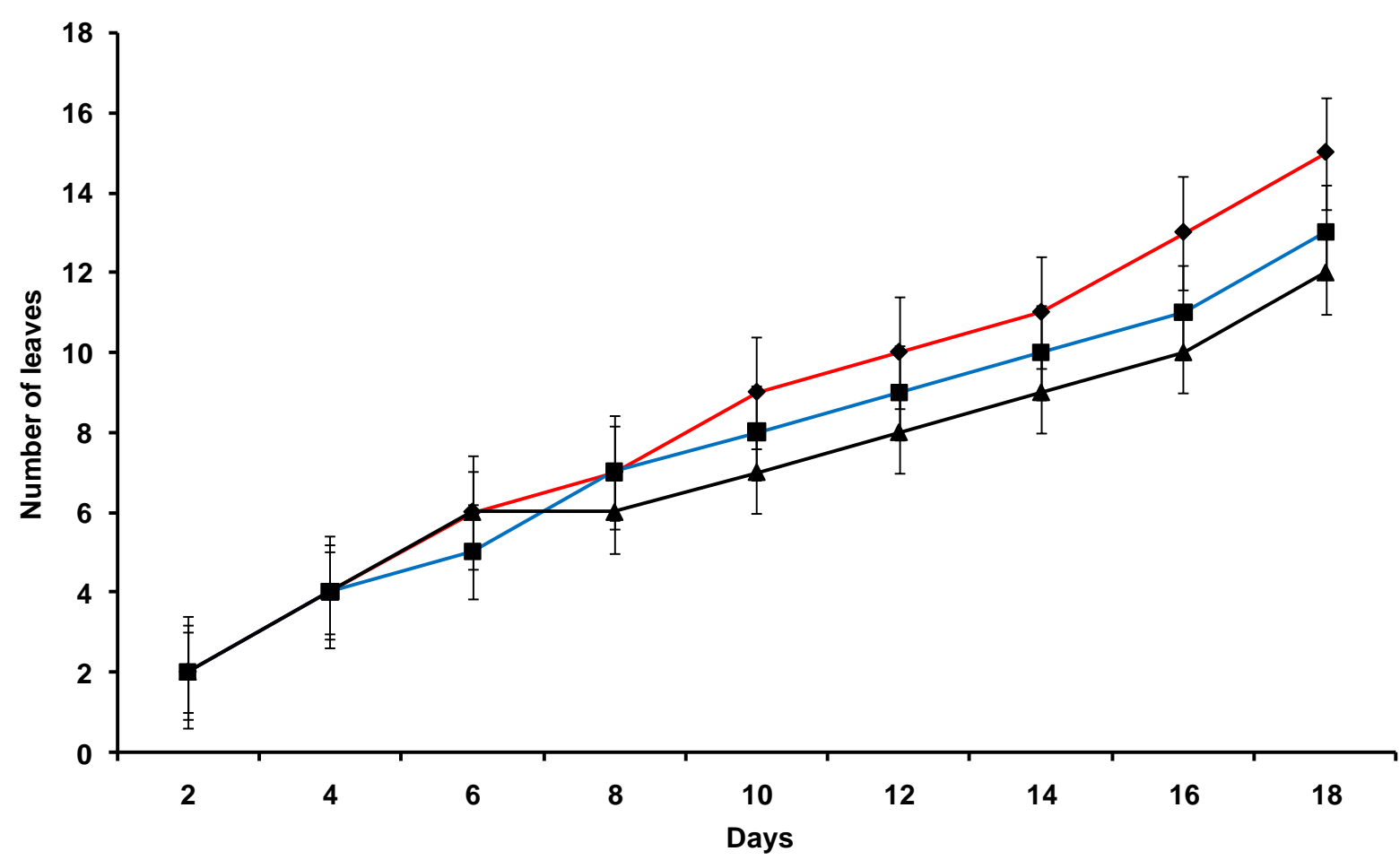

$\bullet \mathrm{A}(13.10-13.05) \rightarrow-\mathrm{B}(11.10-11.05) \quad \leftarrow \mathrm{C}(8.60-8.55)$

FIG. 2. NUMBER OF LEAVES PRODUCED ACCORDING TO THE WEIGHT CLASS

There was a slight deviation from what was observed for the seedling height and leaf number when the leaf area index was observed. At the $8^{\text {th }}$ week the lowest weight class (Fig 3) had the largest leaf area index. The medium weight class had the highest leaf area index at most times throughout the period of this experiment. The weight classes showed a positive correlation with number of leaves and seedling height. For the seedling height, leaf number and leaf area index showed a linear increase over time.

Seed mass effect on Fresh and Dry weight of seedling plants: The differences in the fresh and dry weight for all the weight classes were slight and not significant ( $F=6.1612$ and 3.432 respectively, Table 1, Figs 4 \& 5). There was a strong positive correlation between seed mass with fresh and dry weight of seedlings $(r=0.9221$ and 0.989 respectively, Table 2). The fresh weight of the seedlings showed a strong positive relationship with the number of leaves and also the fresh weight of the seedlings $(r=0.9429$ and 0.9692 respectively, Table 2).

Effect of Cotyledon Removal on Seedling Growth: Cotyledon removal before and after emergence of first foliage leaves resulted in a negative effect on the seedling growth. From Figs $6 \& 7$, it is evident that the rate of reduction in seedling growth increases the more the number of cotyledon removed. The seedlings with one cotyledon removed were taller than those with both cotyledons removed. Also within each group with only one cotyledon removed, the medium weight class showed superiority over the other weight classes in terms of seedlina arowth. This was not the case when both cotvledons were removed as the largest weight class had the highest seedling growth.

\section{DISCUSSION}

Seeds with large mass showed superiority over those with small seed mass for most of the growth parameters observed in the current study. This suggests a positive effect of seed mass on germination and probably an adaptation to establishment in areas with active sand burial where the greater food reserves of large seeds may be an advantage (Cordazzo 2002; Shaukat et al. 1999; Kidson \& Westoby 2000). Large seeds had a higher germination rates that were not significant when compared with those of smaller seeds, contrary to the results of Cordazzo (2002) but agreeing with the work of Bonfil (1998) and Westoby et al., (2002). There is a strong positive correlation between the seed mass and height, leaf number and area index, fresh and dry weight of seedlings

The variation of seed-size of $T$ occidentalis has possible ecological importance in several ways which may depict a compromise between the requirements for dispersal and for establishment (Harper 1977; Swanborough \& Westoby, 1996; Moles and Westoby, 2004). Small seeds are more favoured for wide dispersal compared to larger seeds, which is an added evolutionary advantage (Fenner 1983, Moles and Westoby, 2004); the need for successful establishment creates a selection pressure for large seeds (Lloret et al. 1999; Kidson \& Westoby 2000). Significant differences observed in various growth parameters in African Fluted Pumpkin are related to the ability of the seed to adapt to changes such as limited nourishment from cotyledon removal and limited food from small cotyledons (small seeds). In areas 


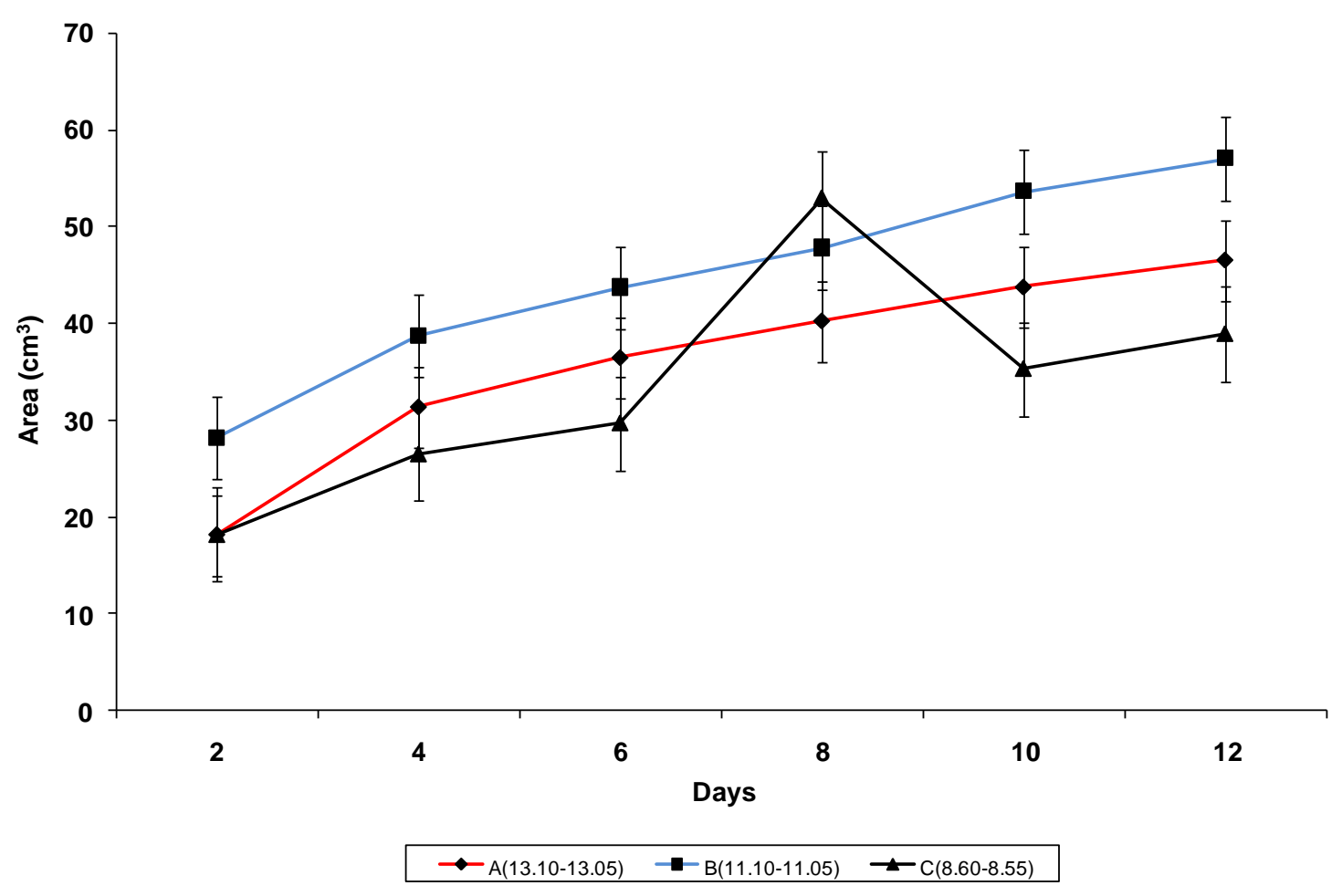

FIG. 3. THE AREA OF LEAVES PRODUCED ACCORDING TO THE SEED WEIGHT CLASS

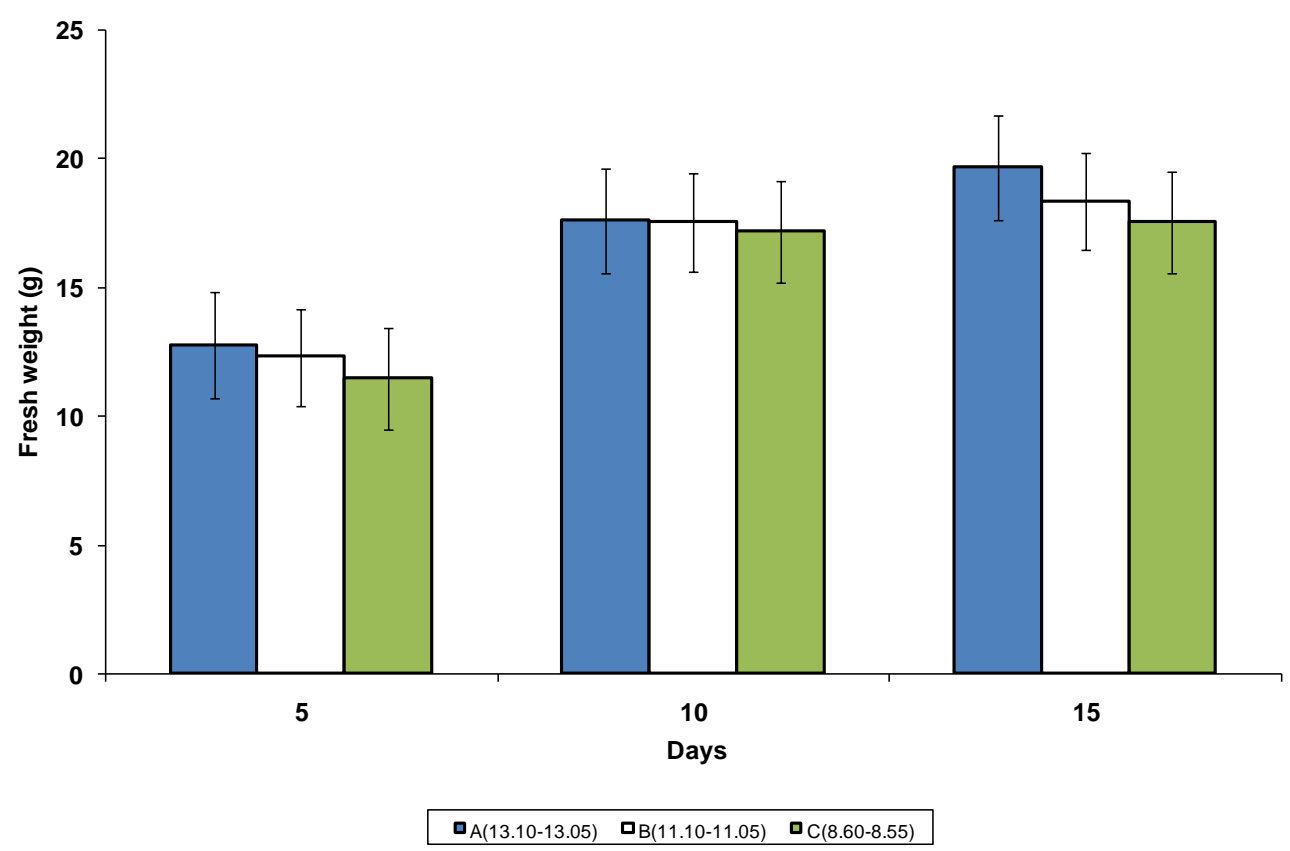

FIG. 4. FRESH WEIGHT OF THESEEDLINGS OF THE DIFFERENT WEIGHT CLASSES 


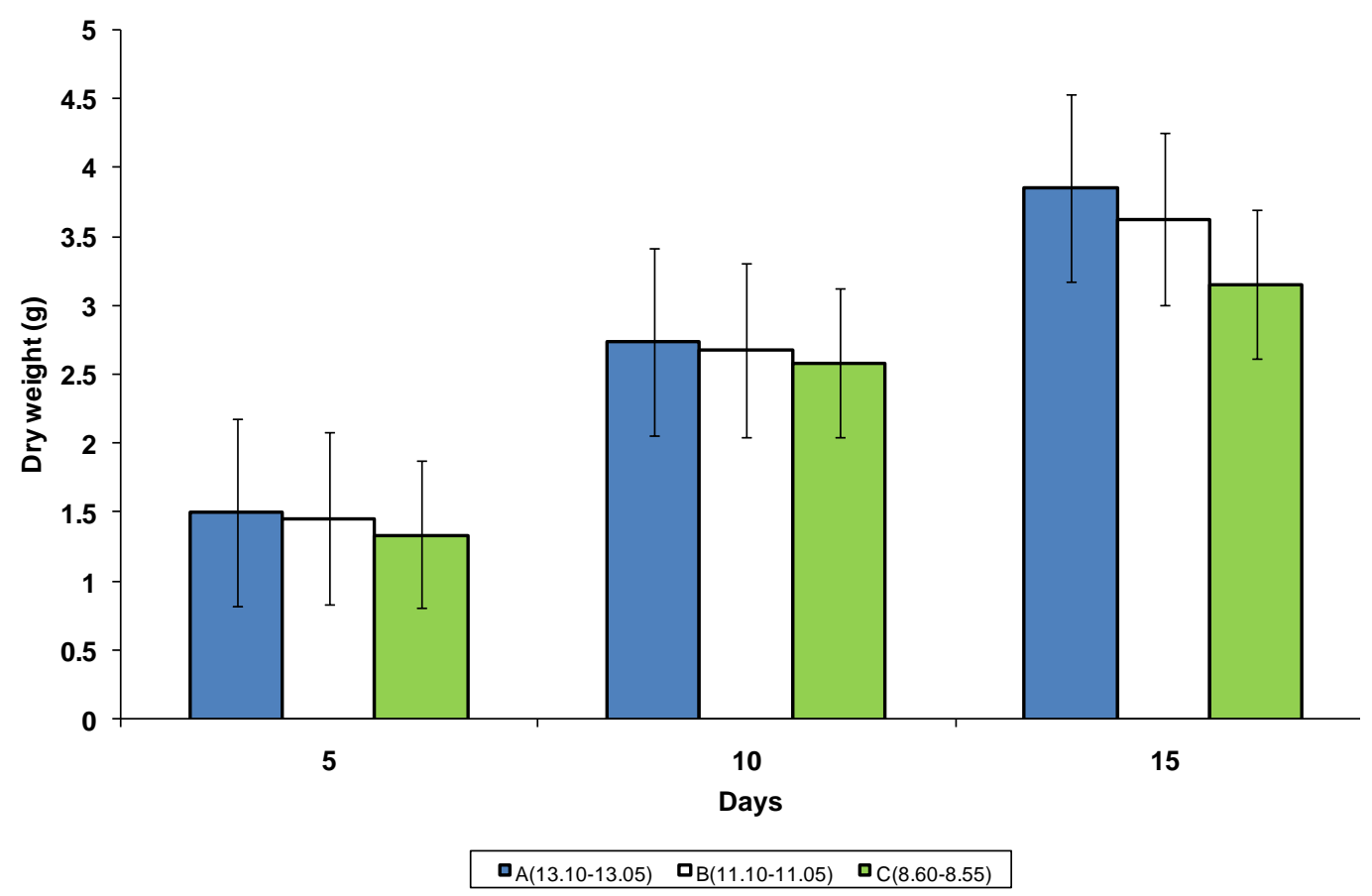

FIG. 5. DRY WEIGHTS OF THE SEEDLINGS OF THE DIFFERENT WEIGHT CLASSES

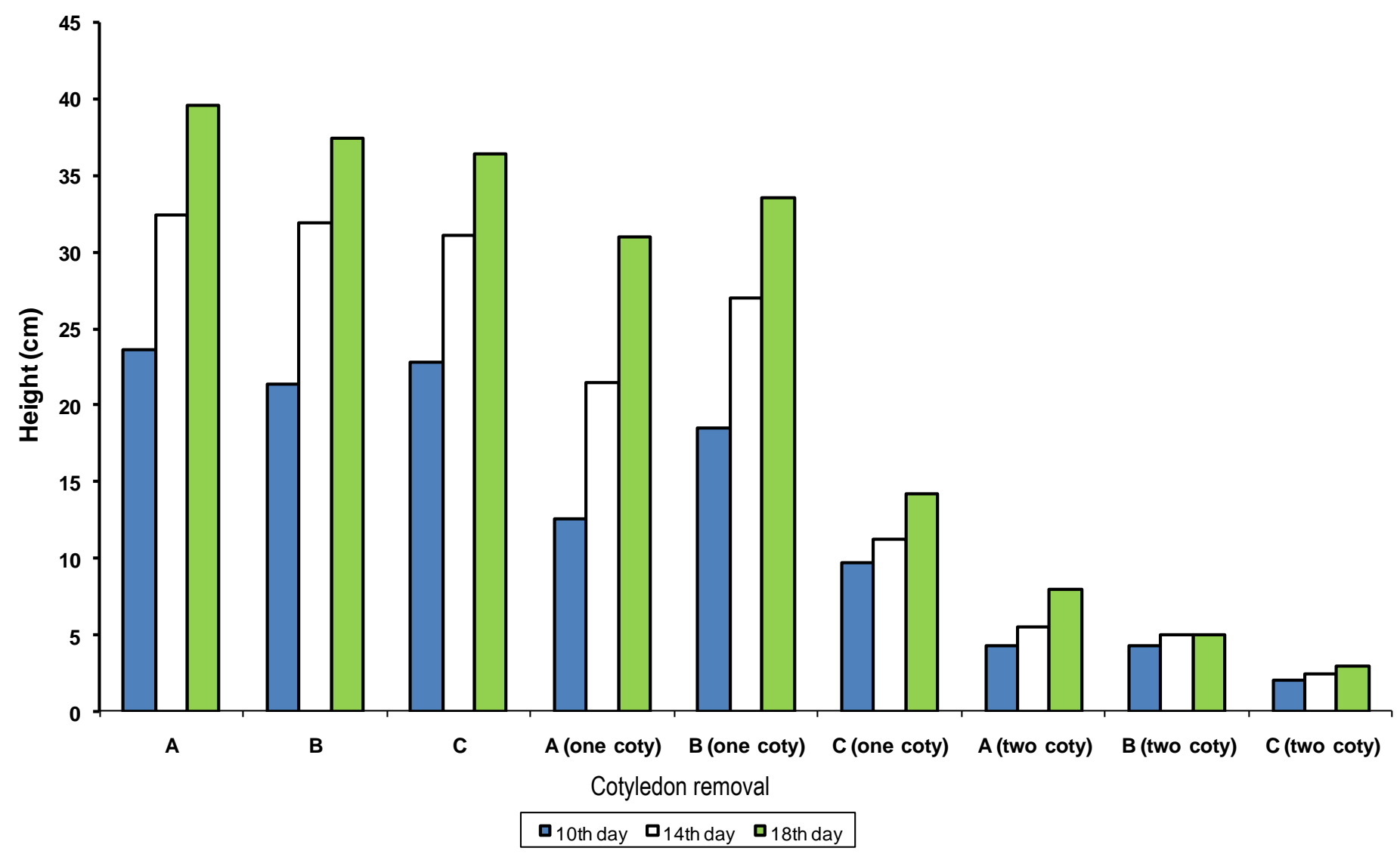

FIG. 6. EFFECTS OF COTYLEDON REMOVAL ON SEEDLING GROWTH BEFORE THE EMERGENCE OF THE FIRST FOLIAGE LEAVES 


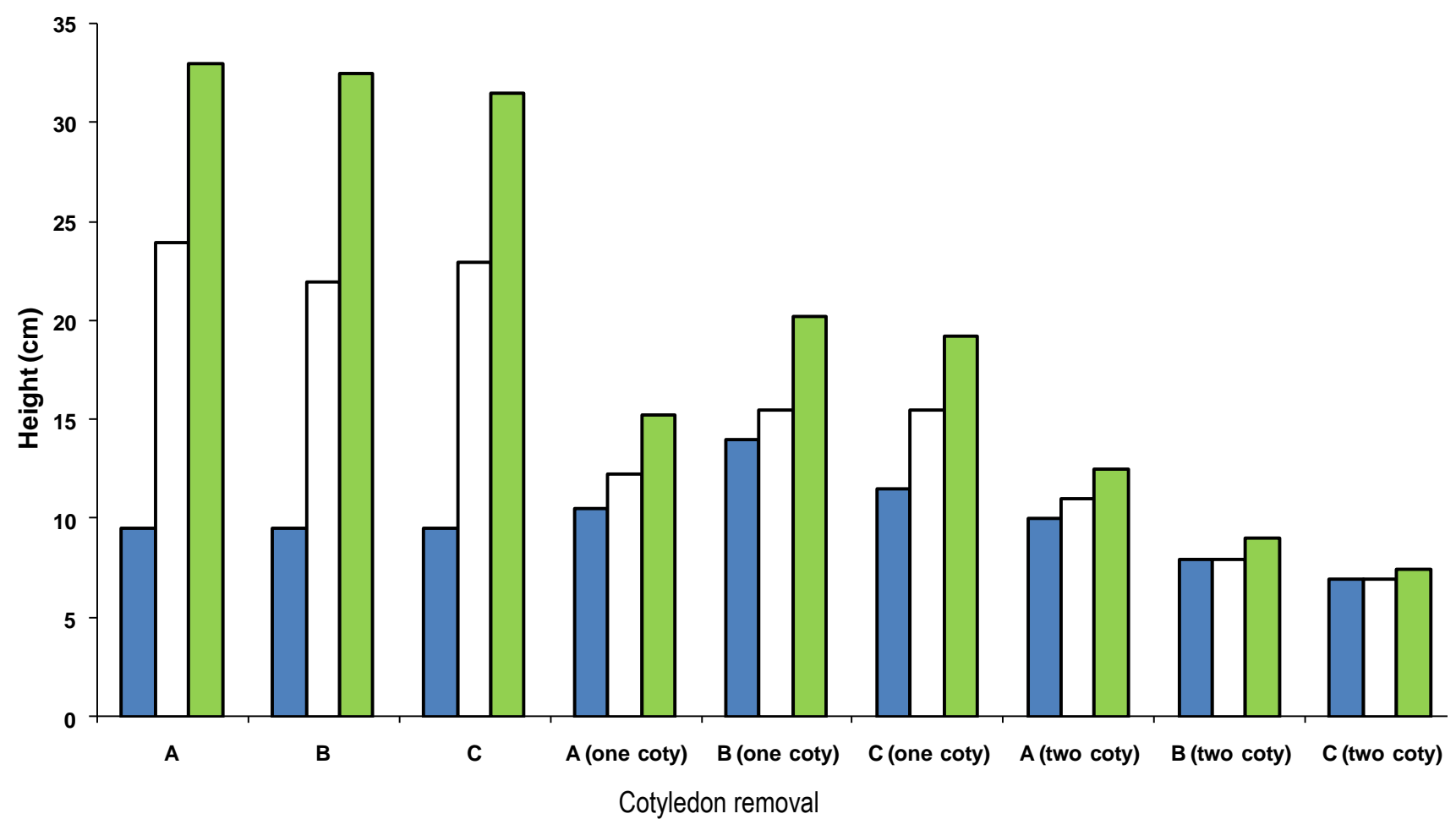

口4th day $\mathbf{Q}_{10 \text { th day }} \mathbf{\square}_{15 \text { th day }}$

FIG. 7. EFFECTS OF COTYLEDON REMOVAL ON SEEDLING GROWTH AFTER THE EMERGENCE OF THE FIRST FOLIAGE LEAVES

where the supply of nutrients is limiting, early germinating seedlings probably have a better chance of growth and establishment when the seed mass is high, agreeing with the works of Cordazzo (1994) on four dominant southern Brazilian coastal species. A small seed implies a small embryo with few food reserves. The seedling from a small seed is dependent from a very early phase in growth on its own independent assimilation. In contrast, the seedling from a large seed may have sufficient reserves to continue growth for a much longer period (Harper 1977; Saverimuttu \& Westoby 1996; Cordazzo 2002).

The significance of the storage role of the cotyledons is a controversial issue. They provide photosynthetic assimilates to promote seedling growth (Marshall \& Kozlowski 1976; Hanley and May, 2006; Myers and Kitajima, 2007). Results from this work indicate that after removal of cotyledons, growth of $T$ occidentalis was dependent solely on the remainder of the cotyledon until the final establishment of the seedling. The residual cotyledon biomass is crucial for the growth and survival of seedlings growing under stressful conditions (Bonfil 1998; Dalling \& Harms 1999; Kitajima 2002). The time of removal of cotyledons is also important in determining whether or not the seedling will survive. When the first foliage leaves are formed, the removal of cotyledons has less severe effect on the seedling growth and establishment, even though it still results in reduction in growth performance. This is supported by the records of Bonfil (1998) who shows that in Quercus laurina, cotyledon removal severely reduce the survival rates of the seedlings, even under moderate conditions. In a related study of $Q$. robur, however, the findings were inconsistent; in some cases cotyledon removal has not affected seedlina arowth and survival. nor rearowth after leaf removal (Sonesson 1994; Andersson \& Frost 1996). Investigations by Frost \& Rydin (1997) and Kitajima (2002) revealed that cotyledon removal did reduce the growth both of seedlings subjected to defoliation and seedlings that were adversely affected by root competition.

The ability of the plant to survive even when both cotyledons were removed indicates that it can recover from attacks from pests, herbivores and diseases that may destroy their aerial biomass including the cotyledon (Bonfil 1998). Although, the removal of cotyledons had additive negative effects on seedling growth and survival over time depending on the number of cotyledons removed or the extent of damage done to the area of seedling biomass, the survival of the seedlings is a positive sign that the plant can survive unfavourable conditions.

In conclusion, large seeds have competitive advantage in germination, seedling establishment and performance. Cotyledon removal reduces seedling establishment rate and performance of $T$ occidentalis. This study indicates that removal (or damage) of cotyledons results in reduction in growth performance of seedlings but not necessarily the ultimate death of the seedling at its early stage of development depending on the degree of removal or damage.

\section{REFERENCES}

Andersson C. \& Frost, I. 1996. Growth of Quercus robur seedlings after experimental grazing and cotyledon removal. Acta Botanica Neerlandica 45:85-94 
Bonfil, C. 1998. The effects of seed size, cotyledon reserves, and herbivory on seedling survival and growth in Quercus rugosa and $Q$. lausina (Fabaceae). American Journal of Botany 85(1):79-87.

Cordazzo, C. V. 1994. Comparative population studies of four dominant plants of southern Brazilian costal dunes. Ph.D. Thesis, University of East Anglia, Norwich, UK.

Cordazzo, C. V. 2002. Effect of seed mass on germination and growth in three dominant species in Southern Brazillian Coastal Dunes. Brazilian Journal of Biology 62:427-434

Dalling J. W. \& Harms, K. E. 1999. Damage tolerance and cotyledonary resource use in the tropical tree Gustavia superba. Oikos $85: 257-264$

Dalling, J. W. \& Hubbell, S. P. 2002. Seed size, growth rate and gap microsite conditions as determinants of recruitment success for pioneer species. Journal of Ecology, 90:557- 568

Fenner, M. 1983. Relationships between seed weight, ash content and seedling growth in twenty-four species of Compositae. New Phytologist 95:697-706

Frost I. \& Rydin, H. 1997. Effects of competition, grazing and cotyledon nutrient supply on growth of Quercus robur seedlings. Oikos $79: 53-58$

Hanley, M. E. \& May, O. C. 2006. Cotyledon damage at the seedling stage affects growth and flowering potential in mature plants. New Phytologist 169:243-250

Harper, J. L. 1977, Population biology of plants. Academic Press, London

Hendrix, S. D. 1984, Variation in seed weight and its effects on germination in Pastinaca sativa L. (Umbelliferae). American Journal of Botany 71:795-802.

Kidson, R. \& Westoby, M. 2000. Seed mass and seedling dimensions in relation to seedling establishment. Oecologia, 125(1):11-17.

Kitajima, K. 2002. Do shade-tolerant tropical tree seedlings depend longer on seed reserves? Functional growth analysis of three Bignoniaceae species Functional Ecology 16 (4):433-444

Kitajima, K. 2003. Impact of cotyledon and leaf removal on seedling survival in Tree species with contrasting cotyldedon functions. Biotropica 33(3):429-434

Lamont, B. B. \& Milberg, P. 1997. Seed/Cotyledon size and nutrient content play a major role in early performance of Species on nutrient poor soils. New Phytologist 137:665-672
Leishman, M. R. \& Westoby, M. 1994. The role of seed size in seedling establishment in dry soil conditions experimental evidence from semi-arid species. Journal of Ecology 82:249-258.

Lloret, F. Casanovas, C. \& Penuelas, J. 1999. Seedling survival of Mediterranean shrubland species in relation to rootshoot ratio, seed size and water and nitrogen use. Functional Ecology 13(2):210-216.

Marshall, P. E. \& Kozlowski, T. T. 1976. Importance of photosynthetic cotyledons for early growth of woody angiosperms. Physiologia Plantarum 37:336-340.

Moles, A. T. \& Westoby, M. 2004. Seedling survival and seed size: a synthesis of the literature. Journal of Ecology 92 (3):372-383

Myers, J. A. \& Kitajima. K. 2007. Carbohydrate storage enhances seedling shade and stress tolerance in a neotropical forest. Journal of Ecology 95(2):383-395

Saverimuttu, T. \& Westoby, M. 1996. Seedling longevity under deep shade in relation to seed size. Journal of Ecology 84:681-689

Shaukat, S. S.; Siddiqui, Z. \& Aziz, S. 1999. Seed size variation and its effects on germination, growth and seedling survival in Acacia nilotica subsp. Indica (Benth.) Brenan. Pakistan Journal of Botany 31(2):253263.

Sonesson, L. K. 1994. Growth and survival after cotyledon removal in Quercus robur seedlings, grown in different natural soil types. Oikos 69:65-70

Swanborough, P. \& Westoby, M. 1996. Seedling relative growth rate and its components in relation to seed size: phylogenetically independent contrasts. Functional Ecology 10:176-184

Weis, M. I. 1982. The effects of propagule size on germination and seedling growth in Mirabilis hirsuta. Canadian Journal of Botany 60:1868-1874.

Westoby, M.; Falster, D.S.; Moles, A.T.; Vesk, P.A. \& Wright, I. J. 2002 Plant ecological strategies: some leading dimensions of variation between species. Annual Review of Ecology and Systematics, 33:125-159.

Zhang. J. \& Maun, M. A. 1991. Effects of partial removal of seed reserves on some aspects of seedling ecology of seven dune species. Canadian Journal of Botany 69:1457-1462.

Zimmerman, J. K. \& Weis, M. I. 1983. Fruit size variation and its effects on germination and seedling growth in Xanthium strumarium. Canadian Journal of Botany 61:2309-2315 